\title{
Solid, double-metal cyanide catalysts for synthesis of hyperbranched polyesters and aliphatic polycarbonates
}

\author{
JOBY SEBASTIAN and SRINIVAS DARBHA* \\ Catalysis Division, CSIR-National Chemical Laboratory and Academy of Scientific and \\ Innovative Research (AcSIR), Pune 411 008, India \\ e-mail: d.srinivas@ncl.res.in
}

MS received 29 October 2013; revised 17 December 2013; accepted 19 December 2013

\begin{abstract}
Fe-Zn and Co-Zn double-metal cyanide (DMC) complexes exhibit highly efficient and selective catalytic activity for synthesis of hyperbranched polyesters (glycerol-succinic acid (G-SA) and glycerol-adipic acid (G-AA)) and aliphatic polycarbonates (via., alternative co-polymerization of cyclohexene oxide and $\mathrm{CO}_{2}$ ), respectively. The influence of method of preparation of $\mathrm{DMC}$, in particular the mode of addition of reagents, on its physicochemical and catalytic properties was investigated. Co-Zn DMC was found highly selective for polycarbonate (than polyethers) formation. Catalysts prepared using tert-butanol and PEG-4000 as complexing and co-complexing agents, respectively, were found superior to those prepared without these agents. Apart from its role as a coordinating ligand, tert-butanol activated the Lewis acidic $\mathrm{Zn}^{2+}$ sites for reactions in polyester and polycarbonate formation. Hydrophobicity, micro-mesoporosity, acid strength and the amount of coordinated complexing agent are some of the crucial factors influenced the catalytic activity of DMC complexes.
\end{abstract}

Keywords. Double-metal cyanide complex; heterogeneous catalysis; hyperbranched polyester; aliphatic polycarbonate; $\mathrm{CO}_{2}$ utilization.

\section{Introduction}

Hyperbranched polymers (HPs) belong to the class of dendritic polymeric architectures. Similar to dendrimers, HPs have a highly branched structural design and a large number of end-groups, but do not have a definite molecular core. They have less defined micro space and often a broad distribution of molecular sizes and shapes. ${ }^{1}$ As a result, dendrimers dominate the fields of highly precise nanotechnology, catalysis and biomedicine, while HPs are more suitable candidates for large scale material engineering applications such as topical drug delivery, biotechnical reactor-based processes, functional and protective coatings, sensors, decontamination and antifouling surfaces, bio-mimetic materials and more strategically for other fields where distributions of molecular sizes are an advantage. Due to the tedious synthesis procedures of dendrimers involving protection, deprotection, and chromatographic separation as compared to the simple synthetic procedures for HPs, the latter have attracted considerable research interest. The synthetic approach of HPs utilizes an $\mathrm{AB}_{x}$-type branched monomer or an $\mathrm{A}_{x}+\mathrm{B}_{y}$ combined monomers $(x, y>2)$, where $\mathrm{A}$ and $\mathrm{B}$ represent two different functional groups that can react

\footnotetext{
*For correspondence
}

with each other but not with themselves. The $\mathrm{A}_{x}+\mathrm{B}_{y}$ strategy has more economic viability, but controlling gelation is a difficult task. The most important intrinsic parameter of HPs is the degree of branching (DB) as it has a significant influence on the physical and chemical properties of the polymer. ${ }^{1,2}$

Glycerol is widely available and rich in functionalities. Its effective utilization is a key factor that can facilitate the economically viable production of biodiesel at commercial scale. Polyesterification of glycerol $(\mathrm{G})$, an $\mathrm{A}_{3}$ monomer with biomass-derived dicarboxylic acids ca., succinic acid (SA) and adipic acid (AA)- $B_{2}$ monomers producing HPs will be a sustainable process for glycerol utilization and its value-addition. Various homogeneous catalysts such as mineral acids and dibutyl tin have been reported for this polymerization. ${ }^{3,4}$ However, issues such as recovery/reuse and air/moisture sensitivity of the homogeneous catalysts and corrosion of the reactor lining in the manufacturing process using these catalysts raise economical and environmental concerns. Further, the polyesters prepared using dibutyl tin catalysts have a low DB of only $48 \% .{ }^{5}$ Use of aprotic solvent to control gelation process and to increase DB caused difficulties in the separation step. ${ }^{6}$ Enzymes catalyse this reaction at ambient conditions, but necessitate longer reaction times $(>48 \mathrm{~h}){ }^{7}$ Controlled gelation 
at high conversions is an issue in these processes. A solid catalyst-based process has engineering, environmental and economic advantages. Recently, we demonstrated that $\mathrm{Fe}-\mathrm{Zn}$ double-metal cyanide (DMC) is an efficient and reusable, solid acid catalyst for producing glycerol-succinic acid (G-SA) and glyceroladipic acid (G-AA) hyperbranched polyesters. ${ }^{8}$ G-SA and G-AA polyesters with high DB at controlled gelation and high conversion of glycerol were obtained over the DMC catalyst.

Carbon dioxide is a greenhouse gas. Its increasing concentration in the earth's atmosphere is becoming a great concern to the scientists worldwide. As a consequence of this, utilization of $\mathrm{CO}_{2}$ in chemicals and fuels synthesis as well as development of processes that do not co-generate $\mathrm{CO}_{2}$ have become research topics of contemporary interest for sustainable development. $\mathrm{CO}_{2}$ is a non-toxic, cheap and renewable $\mathrm{C}_{1}$ building block. Its insertion into aliphatic and alicyclic epoxides producing cyclic carbonates and aliphatic polycarbonates is an attractive approach for its utilization. ${ }^{9}$ Organic carbonates are conventionally synthesized using toxic phosgene $\left(\mathrm{COCl}_{2}\right)$. Replacement of phosgene with $\mathrm{CO}_{2}$ is a novel and sustainable approach in the synthesis of these carbonates. Polycarbonates have applications in packaging, engineering polymers and elastomers. They possess high ductility, good transparency, high heat and impact resistance and biocompatibility for speciality applications. ${ }^{10}$ Alicyclic polycarbonates such as poly(cyclohexene carbonate), possessing higher glass transition temperature are used in lithographic processes for construction of micro fluidic devices. ${ }^{11}$ After Inoue's ${ }^{12}$ discovery of $\mathrm{CO}_{2}$ copolymerization with propylene oxide using $\mathrm{ZnEt}_{2}$ and water system, a number of other catalysts were developed. ${ }^{13}$ Recently, Coates and co-workers ${ }^{14,15}$ developed a series of zinc $\beta$-diiminate complexes which showed superior activity in terms of molecular weight and $\mathrm{CO}_{2}$ insertion. Many comprehensive reviews are available for the different homogeneous catalysts used for epoxide- $\mathrm{CO}_{2}$ coupling. ${ }^{16-21}$ Heterogeneous catalysts, $\mathrm{ZnEt}_{2} /$ protonic compounds $^{12}$ and zinc dicarboxylates ${ }^{22}$ give high polycarbonate selectivity and molecular weight but suffer from low polymer productivity. Double-metal cyanides are well-received catalysts for the homopolymerization of epoxides and copolymerization of epoxides with $\mathrm{CO}_{2}$. Chen et al. ${ }^{23}$ reported poly(cyclohexene carbonate) synthesis over $\mathrm{Co}-\mathrm{Zn}$ DMC with different types of complexing agents. Among them, DMC catalysts prepared with tertbutanol as complexing agent showed maximum conversion (94\% over a reaction period of $2 \mathrm{~h}$ ) with $44.1 \%$ of $\mathrm{CO}_{2}$ incorporation. Yi et al. ${ }^{24}$ used nano DMCs of
Co-Zn and a hybrid of $\mathrm{Co}-\mathrm{Zn}$ and $\mathrm{Fe}-\mathrm{Zn}$ with $\mathrm{ZnCl}_{2}$ and $\mathrm{YCl}_{3}(5-100 \mathrm{~nm})$ for cyclohexene oxide (CHO)$\mathrm{CO}_{2}$ polymerization. The catalyst showed a number average molecular weight $\left(M_{\mathrm{n}}\right)$ of 5100 (polydispersity index, PDI $=1.2$ ) with a maximum of $59 \% \mathrm{CO}_{2}$ incorporation. Dharman et al. ${ }^{25}$ reported microwave-induced copolymerization of $\mathrm{CHO}$ with $\mathrm{CO}_{2}$ over $\mathrm{Co}-\mathrm{Zn}$ catalyst to eliminate the induction period. The polymer was characterised with a $M_{\mathrm{n}}$ of 14500 , PDI of 1.5 and $\mathrm{CO}_{2}$ insertion of $75 \%$. In all these studies, little attention has been paid to detailed characterization of the catalyst and structure-activity correlations. The present study focuses on the influence of method of DMC catalyst preparation on its activity in the synthesis of hyperbranched polyesters of high DB at controlled gelation and poly(cyclohexene carbonate).

\section{Experimental}

$\mathrm{Fe}-\mathrm{Zn}$ and $\mathrm{Co}-\mathrm{Zn}$ DMC catalysts were prepared using tert-butanol as complexing agent and polyethylene glycol of molecular weight 4000 (PEG-4000) as co-complexing agent. Catalysts, Fe-Zn-1, Fe-Zn-2, $\mathrm{Co}-\mathrm{Zn}-1$ and $\mathrm{Co}-\mathrm{Zn}-2$ were prepared by different modes of addition of reagents.

In a typical preparation of $\mathrm{Fe}-\mathrm{Zn}-1,{ }^{26}$ solution 1 was made by dissolving $0.01 \mathrm{~mol}$ of $\mathrm{K}_{4} \mathrm{Fe}(\mathrm{CN})_{6}$ (Merck, India) in double-distilled water. Solution 2 was prepared by dissolving $0.1 \mathrm{~mol}$ of $\mathrm{ZnCl}_{2}$ (Merck, India) in a mixture of distilled water and tert-butanol (5:1 vol/vol). PEG-4000 (15 g) was separately dissolved in distilled water and tert-butanol (1:20 vol/vol) to prepare solution 3 . Solution 2 was added slowly to solution 1 at $50^{\circ} \mathrm{C}$ over $1 \mathrm{~h}$ with vigorous stirring. White precipitation occurred during the addition. Solution 3 was added to the above suspension over a period of $5 \mathrm{~min}$ and stirring was continued for another $1 \mathrm{~h}$. The solid cake formed was filtered, washed with distilled water, and dried at $25^{\circ} \mathrm{C}$ for 2 to 3 days to constant weight.

$\mathrm{Fe}-\mathrm{Zn}-2$ was prepared by mixing solution 2 with solution 3 and then adding this to solution 1 .

Analogous to $\mathrm{Fe}-\mathrm{Zn}-1$ and $\mathrm{Fe}-\mathrm{Zn}-2, \mathrm{Co}-\mathrm{Zn}-1$ and Co-Zn-2 were also prepared using $\mathrm{K}_{3} \mathrm{Co}(\mathrm{CN})_{6}$ precursor and the same complexing and co-complexing agents.

X-ray diffraction (XRD) patterns of DMCs were recorded in the $2 \theta$ range of 5-50 on a Philips X'Pert Pro diffractometer using $\mathrm{Cu}-\mathrm{K} \alpha$ radiation $(\lambda=0.15406 \mathrm{~nm})$ and a proportional counter detector. Specific surface area $\left(S_{\mathrm{BET}}\right)$ of the samples was determined by the Brunauer-Emmett-Teller (BET) method from the $\mathrm{N}_{2}$-adsorption-desorption 
isotherms (NOVA 1200 Quanta Chrome equipment). Average pore diameter was determined by the BarrettJoyner-Halenda (BJH) method. Fourier transform infrared (FTIR) spectra of the samples, as $\mathrm{KBr}$ pellets (1 wt\%), were recorded on a Shimadzu 8201 PC spectrophotometer. Morphological characteristics of the samples were determined using a high-resolution transmission electron microscope (HRTEM; FEI Technai F 30). Density of acid sites was determined by a temperature-programmed ammonia desorption $\left(\mathrm{NH}_{3}\right.$-TPD) technique.

Inverse-gated ${ }^{13} \mathrm{C}$ nuclear magnetic resonance (NMR) spectroscopy was used to analyse DB of the hyperbranched polymer. ${ }^{8,26}$ The measurements were done on a Bruker Avance 500 NMR spectrometer. The various branching and linear segments of the polymer were assigned with the help of distortionless enhancement polarization transfer (DEPT) experiments. Inherent viscosity $(\eta)$ of hyperbranched polymers was measured in tetrahydrofuran (THF) at $29^{\circ} \mathrm{C}$ using an Ubbelhode viscometer. ${ }^{1} \mathrm{H}$ NMR and ${ }^{13} \mathrm{C}$ NMR spectra of polycarbonates were recorded on a Bruker Avance 200 and $500 \mathrm{MHz}$ spectrometer for percentage incorporation of $\mathrm{CO}_{2}$ and percentage tacticity calculations. The $M_{\mathrm{n}}$ and PDI of polycarbonates were determined at room temperature on a PL 220 HT GPC (located at the Polymer Science Division, CSIR-NCL, Pune; injection volume $=100$ microliters) equipped with Styragel columns. Chloroform was used as solvent.

\subsection{Reaction procedure}

2.1a Hyperbranched polyesters: Polyesterification reactions were carried out in a glass reactor placed in a temperature-controlled oil bath. ${ }^{8,26}$ No solvent was used during the polymerization step. Known quantities of diacid (SA or AA) and glycerol (G) were added to the reactor. Contents were flushed with dry nitrogen. Then, DMC catalyst (Fe-Zn-1 or Fe-Zn-2; 3 wt\% of total reactants) was added. Temperature was raised to $160-180^{\circ} \mathrm{C}$ and the reaction was conducted for $1-2 \mathrm{~h}$ while stirring the contents vigorously using a magnetic stirrer and flushing with dry nitrogen gas. At the end, the contents were dissolved in acetone. The catalyst was separated by centrifugation/filtration. Then, the polymer product was reprecipitated from the liquid portion by adding $n$-heptane. Product HP was subjected to characterization.

2.1b Copolymerization of cyclohexene oxide with $\mathrm{CO}_{2}$ : Copolymerization reactions were carried out in a $100 \mathrm{ml}$ stainless steel pressure reactor (Parr 4871, Parr Instrument Co.) equipped with a mechanical stirrer and an automatic temperature control system. A volume of $10 \mathrm{ml}$ each of $\mathrm{CHO}$ and toluene were charged into the reactor along with $0.25 \mathrm{~g}$ of $\mathrm{Co}-\mathrm{Zn}-1$ or $\mathrm{Co}-\mathrm{Zn}-2$ catalyst. The reactor was flushed and then, pressurized with $\mathrm{CO}_{2}$ to 30 bar. Temperature of the reactor was maintained at $75^{\circ} \mathrm{C}$ and the reaction was carried out for $11 \mathrm{~h}$. At the end of the reaction, the catalyst was separated by centrifugation followed by decantation. The solvent toluene was removed over a rotary evaporator. The product was purified by dissolving the solid polymer in dichloromethane, reprecipitating from methanol and drying at $50^{\circ} \mathrm{C}$. The polycarbonate, thus, obtained was subjected to characterization.

\section{Results and discussion}

\subsection{Physicochemical properties of DMC catalysts}

The XRD patterns of Fe-Zn and Co-Zn DMC catalysts (figure 1) could be indexed to cubic lattices. Diffractions arising from (110), (200), (210), (211) and (221) planes of Fe-Zn DMC appeared at $16.4^{\circ}, 19.7^{\circ}, 21.8^{\circ}$, $24.6^{\circ}$ and $28.6^{\circ}$, respectively. Co-Zn catalysts showed reflections at $14.9^{\circ}, 17.2^{\circ}, 24.5^{\circ}$ and $34.9^{\circ}$ related to (200), (220), (400) and (420) planes. Mode of addition of reagents during the synthesis of DMC catalysts influenced marginally the position and full width at half maximum of several reflections. This has affected the unit cell parameter $(a)$ and average crystallite size of the catalysts (tables 1 and 2). Fe-Zn-2 (prepared by mixing solutions 2 and 3 first and then adding this mixture to solution 1) showed broader and lower intensity XRD peaks than $\mathrm{Fe}-\mathrm{Zn}-1$. In the case of $\mathrm{Co}-\mathrm{Zn}$ samples, when the mode of addition of reagents was changed, it showed only a little change in the unit cell parameter. However, the crystallite size was affected drastically. Co-Zn-2 showed larger crystallites than $\mathrm{Co}-\mathrm{Zn}-1$, which is in contrast to $\mathrm{Fe}-\mathrm{Zn}$ catalysts. In addition to that, both the Co-Zn crystals were much bigger than $\mathrm{Fe}-\mathrm{Zn}$ crystals. It is also observed that the unit cell parameter $(a)$ of Co-Zn catalysts is slightly larger than $\mathrm{Fe}-\mathrm{Zn}$ catalysts. This indicates that as the central metal atom in metal cyanides changes, it shows a marginal difference in its crystallization behaviour. Mode of addition of reagents in the synthesis of $\mathrm{Fe}-\mathrm{Zn}$ and $\mathrm{Co}-\mathrm{Zn}$ DMC catalysts resulted in catalysts with different crystalline properties.

Presence of the $\mathrm{CN}$ group bridging the metal atoms $(\mathrm{Fe} / \mathrm{Co}$ and $\mathrm{Zn})$ in DMC catalysts was confirmed by FTIR spectroscopy (figure 2). The precursor compounds, $\mathrm{K}_{4} \mathrm{Fe}(\mathrm{CN})_{6}$ and $\mathrm{K}_{3} \mathrm{Co}(\mathrm{CN})_{6}$ showed $\mathrm{CN}$ stretching bands at 2039 and $2119 \mathrm{~cm}^{-1}$, respectively. ${ }^{27}$ 

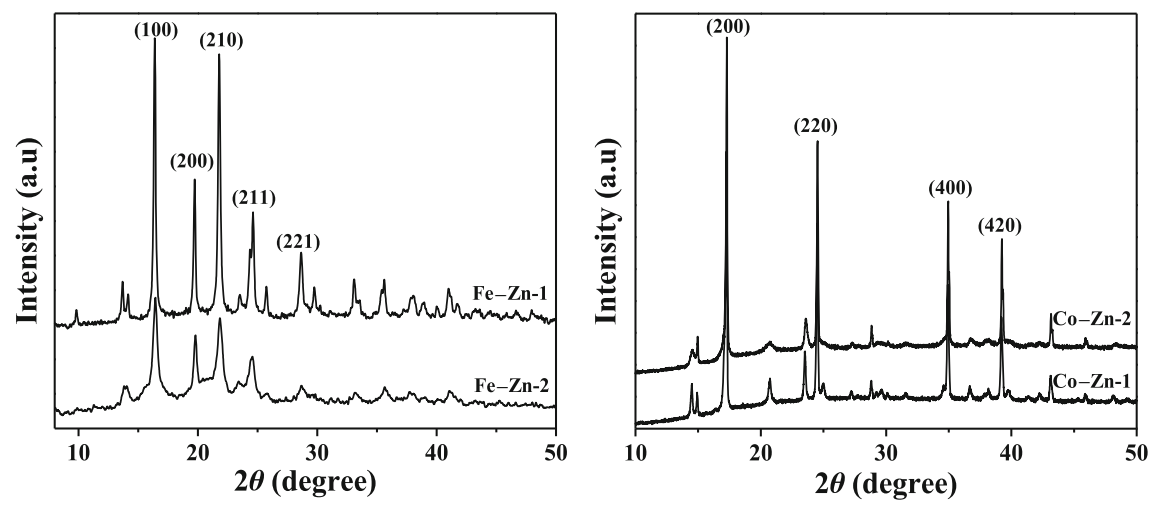

Figure 1. XRD patterns of $\mathrm{Fe}-\mathrm{Zn}$ and $\mathrm{Co}-\mathrm{Zn}$ double-metal cyanide complexes.

The $\mathrm{CN}$ stretching bands in the corresponding $\mathrm{Fe}-\mathrm{Zn}$ and $\mathrm{Co}-\mathrm{Zn}$ complexes were shifted to higher wavelengths at 2096 and $2191 \mathrm{~cm}^{-1}$, respectively. Cyanide ions act not only as $\sigma$-donors by donating electrons to $\mathrm{Fe}$ and $\mathrm{Co}$, but also as $\pi$-donors by bridging to $\mathrm{Zn}$. Presence of coordinated tert-butanol in Fe-Zn catalysts was confirmed from the characteristic bands observed at 2925 (anti-symmetric C-H stretching), 14501249 (symmetric and anti-symmetric $\mathrm{C}-\mathrm{H}$ deformation and out-of-plane $\mathrm{C}_{3} \mathrm{C}-\mathrm{O}$ anti-symmetric stretching vibrations) and $1090 \mathrm{~cm}^{-1}\left(\mathrm{CH}_{3}\right.$ rocking vibrations). Mode of addition of reagents has little effect on the position of $v(\mathrm{CN})$ band at $2096 \mathrm{~cm}^{-1}$, but it broadened the band in the case of $\mathrm{Fe}-\mathrm{Zn}-2$ catalyst. $\mathrm{Fe}-\mathrm{Zn}-2$ showed more intense bands corresponding to coordinated tert-butanol groups than Fe-Zn-1. Co-Zn DMCs showed bands corresponding to tertbutanol groups at 2985, 1278 and $1110 \mathrm{~cm}^{-1}$. Bands at 3651 and $3296 \mathrm{~cm}^{-1}$ correspond to coordinated and $\mathrm{H}-$ bonded water molecules. The band at $1609 \mathrm{~cm}^{-1}$ indicates bending vibration of water molecules. Mode of addition was insensitive to the position but influenced the intensity of the $\mathrm{CN}$ stretching band at $2191 \mathrm{~cm}^{-1}$. $\mathrm{Co}-\mathrm{Zn}-2$ has more intense $\mathrm{CN}$ stretching band than $\mathrm{Co}-\mathrm{Zn}-1$. In contrast to $\mathrm{Fe}-\mathrm{Zn}$ catalysts, mode of addition has resulted in slightly less amount of tertbutanol (band at $1278 \mathrm{~cm}^{-1}$ for C-O stretching and elemental analysis; tables 1 and 2) in Co-Zn-2 than in Co-Zn-1.

Mode of addition of reagents significantly affected the nitrogen adsorption-desorption isotherms and $\mathrm{BJH}$ pore size distribution of $\mathrm{Fe}-\mathrm{Zn}-1$ and $\mathrm{Fe}-\mathrm{Zn}-2$ catalysts. These adsorption isotherms were categorized to type IV with H3 type hysteresis loop and can be regarded as a sign of the existence of some mesopores in the architecture. $\mathrm{Fe}-\mathrm{Zn}-2$ showed three times more specific surface area $\left(S_{\mathrm{BET}}=160 \mathrm{~m}^{2} / \mathrm{g}\right)$ than $\mathrm{Fe}-\mathrm{Zn}-1$ $\left(\mathrm{S}_{\mathrm{BET}}=52 \mathrm{~m}^{2} / \mathrm{g}\right)$. The total pore volume and average pore diameter were also higher for $\mathrm{Fe}-\mathrm{Zn}-2$ than
Fe-Zn-1 (0.15 vs. $0.03 \mathrm{ml} / \mathrm{g}$ and 3.7 vs. $2.5 \mathrm{~nm})$. In the case of $\mathrm{Fe}-\mathrm{Zn}-1$, the microporous area was nearly $74 \%$ of total surface area. HRTEM image further confirmed that these catalysts possess mesopores, ${ }^{8,26}$ although they are not ordered as in the case of Mobils's Crystalline Material (MCM) and Santa Barbara Amorphous (SBA) silica materials.

Acidic properties of the catalysts were evaluated using $\mathrm{NH}_{3}$ as probe molecule. DMCs showed a broad desorption curve in the temperature range of 100$200^{\circ} \mathrm{C}$. The unsymmetric peak was deconvoluted into three desorption peaks. In the case of $\mathrm{Fe}-\mathrm{Zn}$ catalysts, the peak maxima were centred at around $125^{\circ}$, $150^{\circ}$ and $192^{\circ} \mathrm{C}$, respectively. While the first peak was attributed to desorption of physisorbed ammonia, the latter two were assigned to ammonia desorbed from weak and strong Lewis acid sites, respectively. For $\mathrm{Co}-\mathrm{Zn}-2$, the last two peaks occurred at $151^{\circ}$ and $187^{\circ} \mathrm{C}$. These for $\mathrm{Co}-\mathrm{Zn}-1$ appeared at $145^{\circ}$ and $169^{\circ} \mathrm{C}$, respectively. Acidity data of all the catalysts are listed in table $1 . \mathrm{Fe}-\mathrm{Zn}-2$ and $\mathrm{Co}-\mathrm{Zn}-2$ were more acidic than $\mathrm{Fe}-\mathrm{Zn}-1$ and $\mathrm{Co}-\mathrm{Zn}-1$, respectively. Co-Zn-1 contained relatively weaker acid sites showing $\mathrm{NH}_{3}$ desorption peaks at lower temperatures than $\mathrm{Co}-\mathrm{Zn}-2$ indicating the importance of method of preparation on the acidic properties.

Hexacyanometallates are molecular materials formed by assembling of octahedral blocks $\left[\mathrm{M}^{\prime}(\mathrm{CN})_{6}\right]$ through a transition metal $\left(\mathrm{M}^{\mathrm{n}+}\right)$. The metal $\left(\mathrm{M}^{\mathrm{n}+}\right)$ links the neighbouring blocks at $\mathrm{N}$ ends whereby the $\mathrm{CN}$ group act as a bridging ligand $\left(\mathrm{M}^{\prime}\right.$ and $\mathrm{M}$ are $\mathrm{Fe} / \mathrm{Co}$ and $\mathrm{Zn}$ in the present case). ${ }^{28}$ The $\mathrm{CN}$ bridge has extended anti-bonding orbitals at its $\mathrm{C}$ end and is able to withdraw charge from the metal $\left(\mathbf{M}^{\prime}\right) \mathrm{T}_{2 g}$ orbitals through $\pi$-back bonding. This charge is accumulated at the $\mathrm{N}$ end, the coordination site for the second metal $\left(\mathrm{M}^{\mathrm{n}+}\right)$. The net consequence is interaction between the electron clouds of two metals through the $\mathrm{CN}$ ligand. $\mathrm{X}$-ray structure of $\mathrm{Fe}-\mathrm{Zn}$ DMC could not be reported 

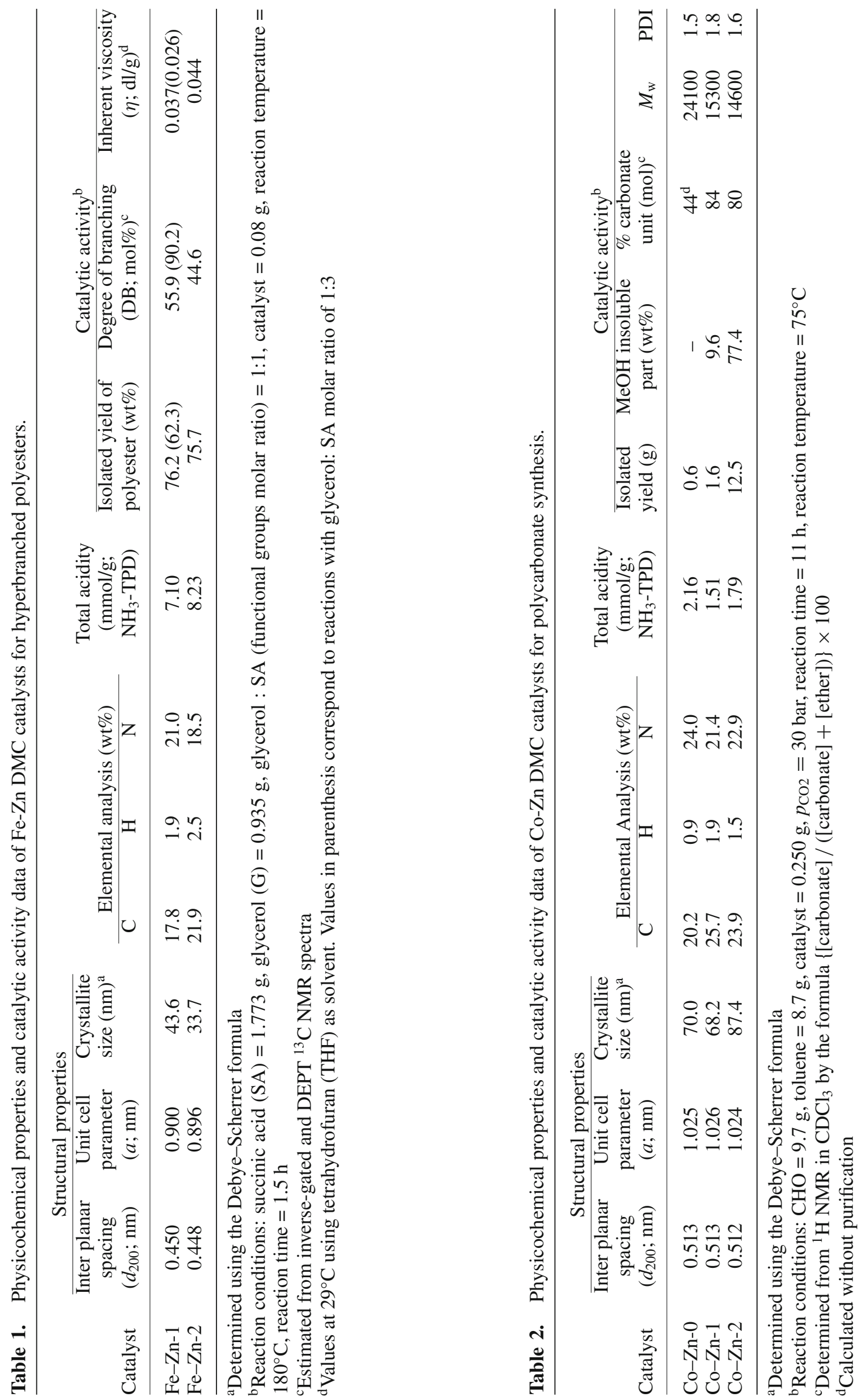
so far due to difficulties in obtaining good quality single crystals. FTIR spectra provided evidence for cyanobridged coordination between $\mathrm{Fe}^{2+}$ and $\mathrm{Zn}^{2+}$ ions $\left(v(\mathrm{CN})\right.$ band at $2096 \mathrm{~cm}^{-1}$ ) and also for the presence of coordinated tert-butanol molecules (bands at 2925, 1450-1249, $1090 \mathrm{~cm}^{-1}$ ). Based on the spectral studies and molecular formula derived from elemental analysis $\left\{\mathrm{K}_{4} \mathrm{Zn}_{4}\left[\mathrm{Fe}(\mathrm{CN})_{6}\right]_{3} \cdot 6 \mathrm{H}_{2} \mathrm{O}\right.$. $x$ (tert-butanol), where $x=$ $1-2\}$, a tentative structure was proposed. ${ }^{8,26}$ In this structural arrangement, each $\mathrm{Fe}^{2+}$ ion has an octahedral geometry coordinated with six $\mathrm{CN}^{-}$groups, while $\mathrm{Zn}^{2+}$ has a tetra-coordinated structure. Zinc ions are either coordinated with $\mathrm{N}$-atoms of four bridging $\mathrm{CN}$ groups or with two cyanides and one each of tertbutanol and water molecules. A few molecules of water are present in the structure as solvent of crystallization. Potassium ions act as charge compensating counter ions. The Lewis acidic tetra-coordinated $\mathrm{Zn}^{2+}$ ions are the active sites in polyesterificaton reactions. Crystal structure of $\mathrm{Co}-\mathrm{Zn}$ complexes was reported. ${ }^{28-30}$ In the crystal structure, Co is octahedrally coordinated by $\mathrm{C}$ atoms of six $\mathrm{CN}$ ligands and the $12 \mathrm{~N}$ ends, are shared by $3 \mathrm{Zn}$ atoms. So each $\mathrm{Zn}$ atom gets an average coordination of $4 \mathrm{~N}$ ends. Remaining coordination is satisfied by water molecules and/or complexing agents. Water molecules can be removed by thermal treatment leaving coordinatively unsaturated sites as active centres for polycarbonate synthesis.

\subsection{Catalytic activity}

3.2a Hyperbranched polyesters: Figure 3 shows representative inverse-gated and DEPT ${ }^{13} \mathrm{C}$ NMR spectra of isolated G-SA hyperbranched polymer. Peaks corresponding to different branched segments of the polymers are marked in the spectrum. The degree of branching (DB) was calculated using Frey's equation: ${ }^{1}$

$$
D B=2 D /\left(2 D+L_{12}+L_{13}\right),
$$

where $D=$ area of the NMR peak due to dendritic unit with all the hydroxyl groups of glycerol esterified and $L_{12}$ and $L_{13}$ are linear segments with 1,2- and 1,3hydroxyl groups esterified. Segments with only one hydroxyl group of glycerol esterified (terminal $\mathrm{T}_{12}$ and $\mathrm{T}_{13}$ ) and the acid terminal groups $\left(\mathrm{T}_{\mathrm{A}}\right)$ are usually not considered in DB estimation (figure 4). Table 1 lists the catalytic activity data of $\mathrm{Fe}-\mathrm{Zn}-1$ and $\mathrm{Fe}-\mathrm{Zn}-2$ catalysts in the synthesis of G-SA hyperbranched polymers. As discussed earlier, when the mode of addition of reagents in the synthesis was changed, it resulted in catalysts with different textural and structural properties (crystallite size, total acidity and surface area). In spite of having higher surface area, smaller crystallite size and higher total acidity, Fe-Zn-2 exhibits lower catalytic activity than Fe-Zn-1 (table 1). In order to check the effect of acidity on catalytic activity, the reaction was conducted with highly acidic Amberlyst70 catalyst. The reaction mixture gelled within $20 \mathrm{~min}$ leaving a DB of only $42 \mathrm{~mol} \%$. This observation indicates that acidity is not the only parameter deciding catalytic activity. This experiment also confirms that while acidic sites are important, surface architecture plays a vital role in limiting gelation and controlling DB of the polymer. To obtain a better insight into the surface architecture of Fe-Zn catalysts, Fe-Zn-0 DMC was prepared without adding both the complexing and the co-complexing agents in the synthesis medium to generate a microporous architecture. $\mathrm{Fe}-\mathrm{Zn}-0$ has an overall acidity of $3.5 \mathrm{mmol} / \mathrm{g}$. DB and isolated yield of polymer obtained using $\mathrm{Fe}-\mathrm{Zn}-0$ were lower (49.5 mol\% and $53.8 \mathrm{wt} \%$, respectively) than the most effective catalyst, $\mathrm{Fe}-\mathrm{Zn}-1$ prepared with tert-butanol as complexing and PEG-4000 as co-complexing agents (55.9 $\mathrm{mol} \%$ and $76.2 \mathrm{wt} \%$, respectively). Moreover, gelation of the polymer started occurring at $1.2 \mathrm{~h}$ itself (at $180^{\circ} \mathrm{C}$ ) with $\mathrm{Fe}-\mathrm{Zn}-0$, while such gelation was not detected even at $1.8 \mathrm{~h}$ with $\mathrm{Fe}-\mathrm{Zn}-1$ catalyst reconfirming the importance of complexing and co-complexing agents in catalyst synthesis. Presence of complexing and co-complexing agents is crucial for inducing mesoporosity to the catalysts. Co-complexing agent acts as surfactant during the synthesis of $\mathrm{Fe}-\mathrm{Zn}-1$ and $\mathrm{Fe}-\mathrm{Zn}-2$ catalysts. In this context, mesoporosity and hydrophobicity of the catalyst surface are considered for elucidating better catalytic activity from $\mathrm{Fe}-\mathrm{Zn}-1$ catalyst. Fe-Zn-2 has larger pores than Fe-Zn-1 (3.7 nm as against $2.5 \mathrm{~nm}$ ). Though large diameter pores will reduce diffusional limitations during the reaction, high stirring speed can overcome diffusional limitations in Fe-Zn-1 to give high yield and DB. Hydrophobic behaviour of catalyst surface is crucial for esterification reactions since water is formed as byproduct. Relative hydrophobicity of $\mathrm{Fe}-\mathrm{Zn}$ catalysts was monitored by water adsorption followed by theromgravimetric analysis (Supplementary information, S1). ${ }^{26} \mathrm{Fe}-\mathrm{Zn}-1$ (water adsorption capacity $=15 \mathrm{wt} \%$ ) was found to be more hydrophobic than Fe-Zn-2 catalyst (water adsorption capacity $=18 \mathrm{wt} \%$ ). Surface hydrophobicity of FeZn-1, similar to silicalite-1 molecular sieve, facilitates adsorption of acids but not the co-product water formed during polyesterification reaction. Hence, Lewis acidity, mesoporosity and hydrophobicity are the critical parameters control the preparation of hyperbranched polyesters of high DB without gelation. Fe-Zn-1 possesses the right combination of these three factors for higher catalytic activity. 

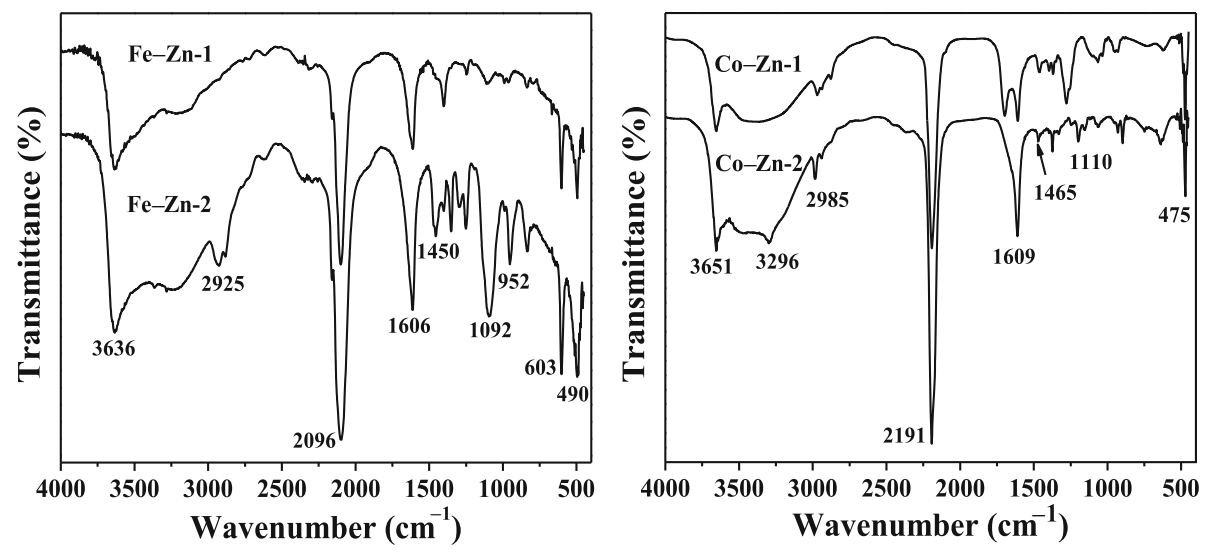

Figure 2. FTIR spectra of $\mathrm{Fe}-\mathrm{Zn}$ and $\mathrm{Co}-\mathrm{Zn}$ double-metal cyanide complexes.

As temperature increased from $160^{\circ}$ to $180^{\circ} \mathrm{C}$, DB for G-SA polymer increased from 29 to $56 \mathrm{~mol} \%$ and the isolated yield of the polymer increased from 62 to $76 \mathrm{wt} \%$. Further raise in reaction temperature to $190^{\circ} \mathrm{C}$ did not result in a major increase of DB (56 mol\%); the isolated yield of the polymer decreased to $53 \mathrm{wt} \%$ due to formation of anhydrides, which led to lower concentration of SA in the reaction (Supplementary information, S2). G-AA had shown a linear increase in DB from 14 to 59 mol\% as the temperature was increased from $160^{\circ}$ to $190^{\circ} \mathrm{C}$. Molar ratio of diacid to glycerol functional groups too had a marked effect on polymer properties (Supplementary information, S3). When molar ratio was increased from 1 to 2 , DB increased from 56 to $90 \mathrm{~mol} \%$. Viscosity values confirmed that polymers are not cross-linked $(0.026 \mathrm{dl} / \mathrm{g})$ and the reaction mixture is not a sol and gel system. ${ }^{31}$ In the case of G-AA polymer,
DB value increased from 38 to $85 \mathrm{~mol} \%$ as the molar ratio increased from 1 to 2 . DB decreased with increase in chain length of the diacid. Such decrease in DB can be attributed to a combination of polar (inductive effect) and steric influences of the $\alpha$-substituent on the carboxylic acid group. However, above $\mathrm{C}_{4}$ chain length, variations in rate are attributed to steric factors only. ${ }^{32}$

In a proposed catalytic cycle, micro-meso pores in the catalyst were presumed to act as nano-reactors for primary condensation of $\mathrm{A}_{2}+\mathrm{B}_{3}$ molecules to form $\mathrm{AB}_{2}$ type reaction intermediates. ${ }^{26}$ Due to steric constraints, further polymerization of these monomers is not expected to continue inside the pores. So, the initial time period of the reaction would be the generation of $\mathrm{AB}_{2}$ type monomers and its further propagation to dendritic architectures will continue on the external surface. Reactivity difference between primary

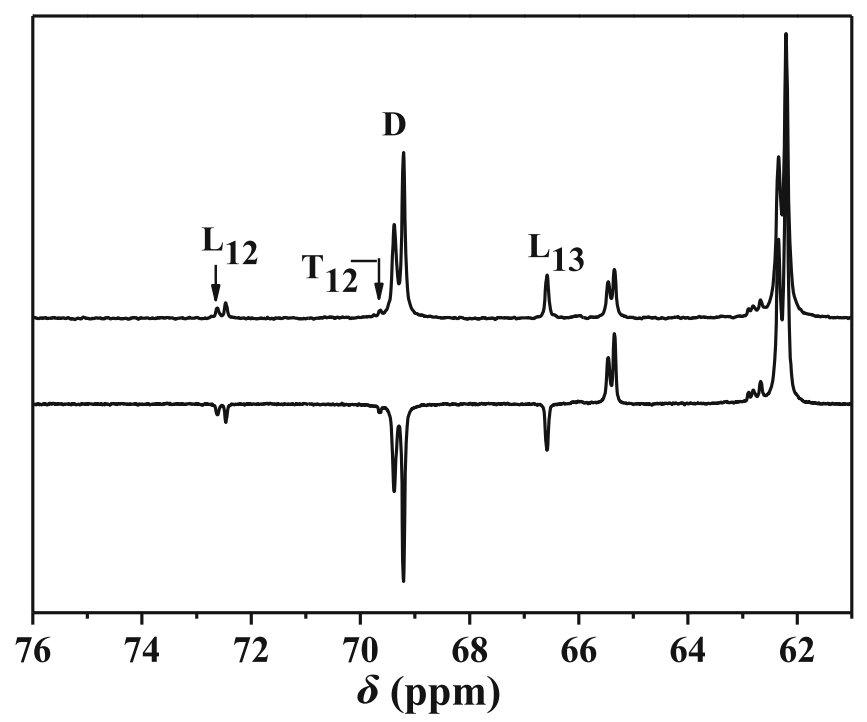

Figure 3. Inverse-gated (top) and DEPT (bottom) ${ }^{13} \mathrm{C}$ NMR spectra of G-SA hyperbranched polymer. 


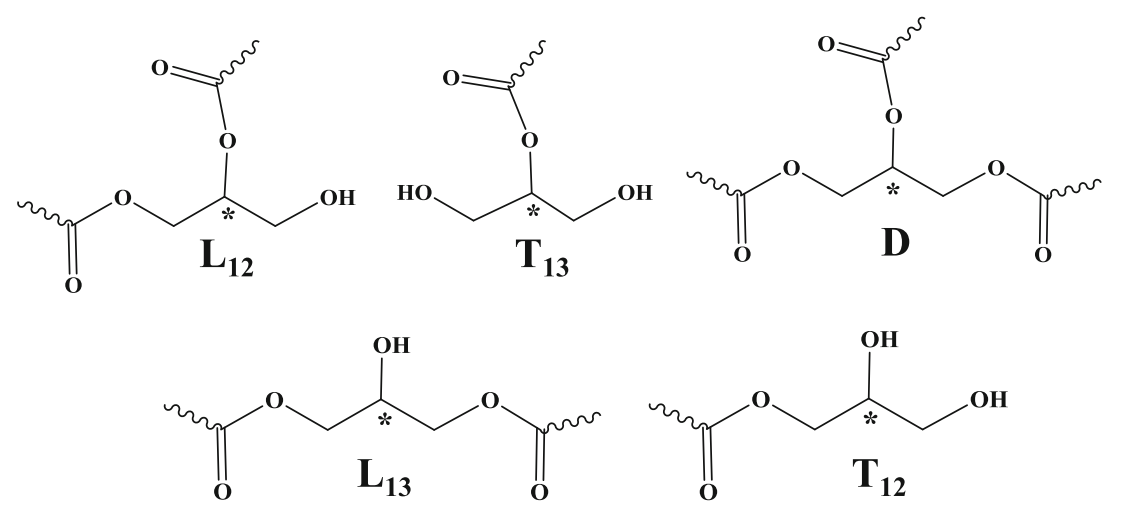

Figure 4. Various branching segments of G-SA hyperbranched polyester. NMR signals corresponding to marked carbons were used in DB calculation.

and secondary $-\mathrm{OH}$ groups on the circumference controls the cross-linking rate between different dendritic molecules. Hydrophobic nature of surface active sites preserves catalytic activity by reducing interaction with polar water molecules. Altogether, it is found that, Lewis acid sites to initiate the polymerization reaction, micro-meso porous architecture to control the gelation phenomenon and surface hydrophobicity are the critical parameters of $\mathrm{Fe}-\mathrm{Zn}$ DMC catalysts for synthesizing biodegradable hyperbranched polymers with high degree of branching.

\section{2b Copolymerization of cyclohexene oxide with $\mathrm{CO}_{2}$ :} Figure 5 shows the ${ }^{1} \mathrm{H}$ NMR spectrum of purified poly(cyclohexene carbonate) prepared over $\mathrm{Co}-$ $\mathrm{Zn}$ DMC catalysts. Methine protons near carbonate linkages showed signals from $\delta=4.2$ to $4.6 \mathrm{ppm}$ and those near ether linkages were observed at $\delta=$ 3.2 to $3.6 \mathrm{ppm}$. Percentage incorporation of $\mathrm{CO}_{2}$ was calculated with the integrated values using the formula $\{[$ carbonate $] /([$ carbonate $]+[$ ether $])\} \times 100$. Catalyst prepared without complexing and co-complexing agent (Co-Zn-0) did not show any activity (table 2 ). Although it has good crystallinity (crystallite size $=70 \mathrm{~nm}$ ) and acidity $\left(2.16 \mathrm{mmol} / \mathrm{g} \mathrm{NH}_{3}\right.$ ), catalytic activity was too low even at a longer reaction period of $11 \mathrm{~h}$. As complexing and co-complexing agents were introduced into the synthesis medium, catalysts showed a switch over in their catalytic activity. Therefore, incorporation of tert-butanol is essential for inducing catalytic activity in Co-Zn DMC. As the mode of addition of reagents was changed during catalyst synthesis, the generated catalysts showed drastically different activity patterns. $\mathrm{Co}-\mathrm{Zn}-2$ resulted in a complete $\mathrm{CHO}$ conversion with an isolated yield of $12.5 \mathrm{~g}$ of polymer and a carbonate unit incorporation of $80 \mathrm{~mol} \%$. An increase in weight of polymer product with respect to weight of $\mathrm{CHO}$ taken $(9.7 \mathrm{~g})$ undoubtedly designates incorporation of $\mathrm{CO}_{2}$ units in the polymer matrix (poly ether formation does not reflect in any weight gain). In contrast, Co-Zn-1 showed only little $\mathrm{CHO}$ conversion with $84 \mathrm{~mol} \%$ of carbonate unit incorporation. This result clearly shows that even subtle changes in catalyst synthesis can impart great influence on catalytic activity. Elemental analysis showed higher amount of carbon and hydrogen in $\mathrm{Co}-\mathrm{Zn}-1$ than in $\mathrm{Co}-\mathrm{Zn}-2$ (C and $\mathrm{H}$ are $25.7 \%$ and $1.9 \%$ versus $23.9 \%$ and $1.5 \%$ ) indicating that

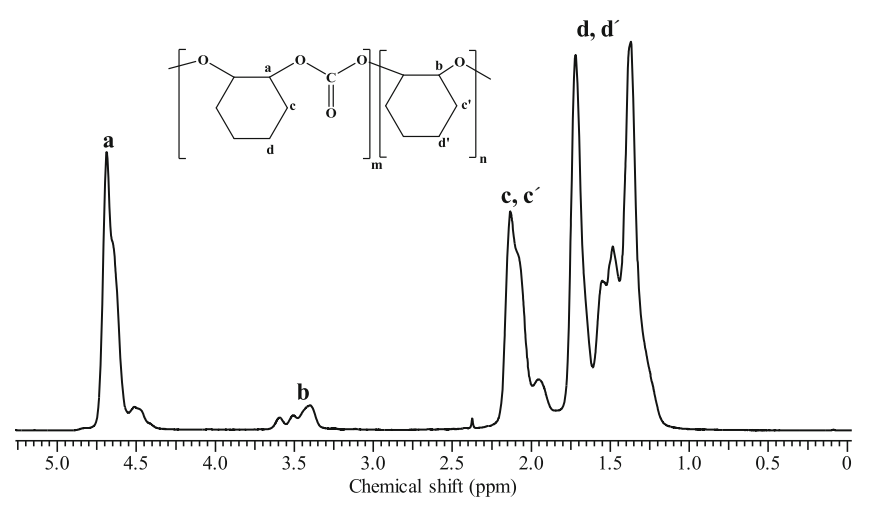

Figure 5. ${ }^{1} \mathrm{H}$ NMR spectra of poly(cyclohexene carbonate). 


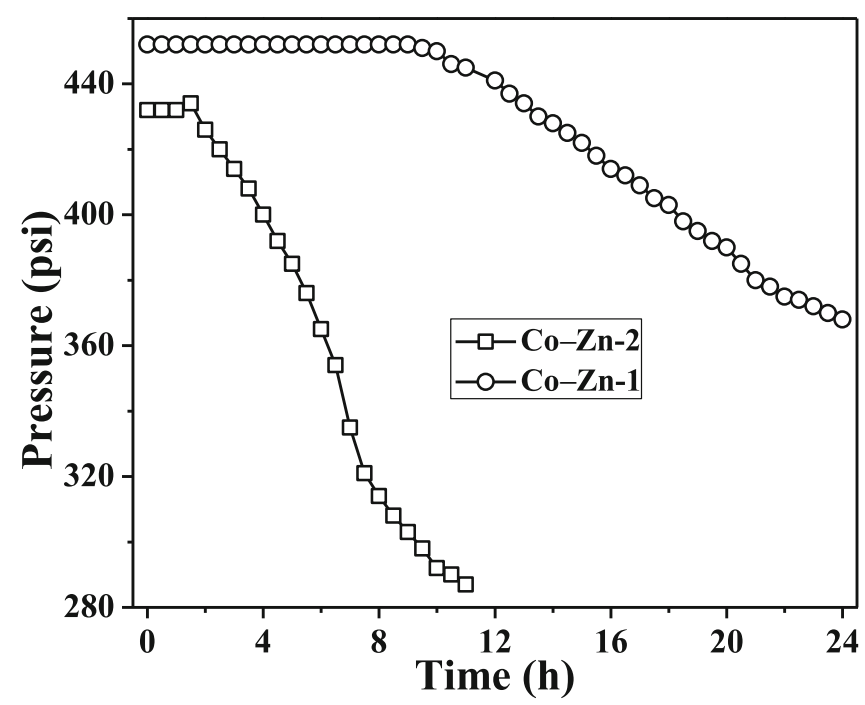

Figure 6. $\mathrm{CO}_{2}$ consumption as a function of time in polycarbonate synthesis over $\mathrm{Co}-\mathrm{Zn}-1$ and $\mathrm{Co}-\mathrm{Zn}-2$ catalysts.

Co-Zn-1 contains higher amount of complexing agent than $\mathrm{Co}-\mathrm{Zn}-2$. In addition, acidity measurement showed that $\mathrm{Co}-\mathrm{Zn}-1$ is less acidic than $\mathrm{Co}-\mathrm{Zn}-2$ (1.5 versus $1.79 \mathrm{mmol} \mathrm{NH}_{3} / \mathrm{g}$ ). Strength of acid sites in $\mathrm{Co}-\mathrm{Zn}-1$ was weaker than in $\mathrm{Co}-\mathrm{Zn}-2$. There were some reports that catalytic activity is due to amorphous nature of DMC. However, both Co-Zn-2 and Co-Zn0 were crystalline, while Co-Zn-2 is highly active and $\mathrm{Co}-\mathrm{Zn}-0$ is little active. This points out that amorphous nature of the material is not responsible for the activity. Again $\mathrm{Co}-\mathrm{Zn}-0$ is more acidic than $\mathrm{Co}-\mathrm{Zn}-1$. However, $\mathrm{Co}-\mathrm{Zn}-0$ contains weaker acid sites than $\mathrm{Co}-\mathrm{Zn}-1$ and $\mathrm{Co}-\mathrm{Zn}-2\left(\mathrm{NH}_{3}\right.$ desorption peak centred at $160^{\circ} \mathrm{C}$ in $\mathrm{Co}-$ $\mathrm{Zn}-0$ as against $169^{\circ}$ and $187^{\circ} \mathrm{C}$ in $\mathrm{Co}-\mathrm{Zn}-1$ and $\mathrm{Co}-$ $\mathrm{Zn}-2$, respectively). So, presence of adequate amount of complexing agent and stronger acid sites are crucial parameters governing catalytic activity of $\mathrm{Co}-$ $\mathrm{Zn}$ catalysts. Figure 6 depicts $\mathrm{CO}_{2}$ consumption in the reaction as a function of time over $\mathrm{Co}-\mathrm{Zn}$ catalysts. It is well-known that DMC catalysts show an induction period in polyether synthesis. ${ }^{33} \mathrm{CO}_{2}$ pressure was found constant up to $9 \mathrm{~h}$ for $\mathrm{Co}-\mathrm{Zn}-1$ and then dropped slightly afterwards. Percentage incorporation of $\mathrm{CO}_{2}$ in the polymer was $84 \mathrm{~mol} \%$ at the end of $11 \mathrm{~h}$. This catalyst is highly selective for polycarbonate than for polyether formation. Co-Zn-2 shows an induction period of only $2 \mathrm{~h}$ (instead of $9 \mathrm{~h}$ with Co-Zn-1) and thereafter, a large pressure drop of $\mathrm{CO}_{2}$ was observed. Yield of polycarbonate at the end of $11 \mathrm{~h}$ was $12.5 \mathrm{~g}$ with $80 \mathrm{~mol} \%$ carbonate unit incorporated.

To explore the difference in $\mathrm{CO}_{2}$ activation of $\mathrm{Co}-\mathrm{Zn}-1$ and $\mathrm{Co}-\mathrm{Zn}-2, \mathrm{CO}_{2}$ adsorption studies were conducted. The $\mathrm{CO}_{2}$ adsorption isotherms show marginal difference between $\mathrm{Co}-\mathrm{Zn}-1$ and $\mathrm{Co}-\mathrm{Zn}-2$ (figure 7). Krap et al..$^{34}$ stated that at low pressure values, guest-guest interactions are minimized and the isotherm slope can be taken as a sensor for the strength of the guest-host interaction. From the isotherm it is clear that $\mathrm{Co}-\mathrm{Zn}-2$ has much steeper slope than Co-Zn-1, which means higher guest-host interaction than in $\mathrm{Co}-\mathrm{Zn}-1$. This can be correlated to catalytic activity of $\mathrm{Co}-\mathrm{Zn}-2$ and $\mathrm{CO}_{2}$ activation/incorporation in the polymer. Higher guest-host interaction reduces induction period of $\mathrm{Co}-\mathrm{Zn}-2$ catalyst.

${ }^{13} \mathrm{C}$ NMR spectrum of the polymer was collected to reveal tacticity pattern (Supplementary information, S4). The spectrum was found similar to those reported with $\beta$-diiminate complexes. ${ }^{35}$ Signal at $153.8 \mathrm{ppm}$ corresponds to isotactic isomers, whereas signals at 153.1 to $153.3 \mathrm{ppm}$ correspond to syndiotactic isomers. The signal for isotactic isomer arises from the carbonyl carbons of $\mathrm{m}$-centred tetrad $(\mathrm{mmm} / \mathrm{mmr} / \mathrm{rmr})$ and those for syndiotactic isomer come from $\mathrm{r}$-centred tetrads $(\mathrm{rrr} / \mathrm{rrm} / \mathrm{mrm}){ }^{36}$ Percentage of isotacticity in the polymer was estimated to be $47.6 \%$ and it is apparent that the catalyst does not show any selectivity to a preferred configuration. The IR spectrum of the polymer (Supplementary information, S5) showed a band at $1745 \mathrm{~cm}^{-1}$ corresponding to stretching vibration of the carbonyl group. A band at $2918 \mathrm{~cm}^{-1}$ indicated $-\mathrm{CH}$ stretching vibration. Bands at 970 and $1250 \mathrm{~cm}^{-1}$ corresponded to $\mathrm{C}-\mathrm{O}$ stretching vibration in the polymer. The band at $770 \mathrm{~cm}^{-1}$ was ascribed to the $-\mathrm{OH}$ bending of terminal groups. A small band at $3650 \mathrm{~cm}^{-1}$ corresponding to $-\mathrm{OH}$ stretching vibrations

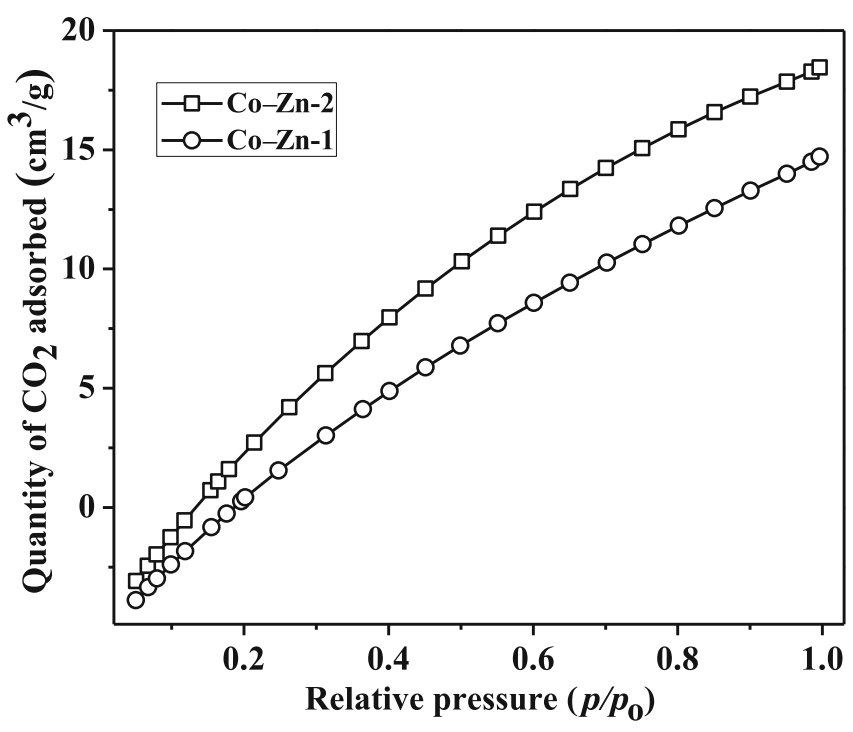

Figure 7. $\mathrm{CO}_{2}$ adsorption isotherm of $\mathrm{Co}-\mathrm{Zn}-1$ and $\mathrm{Co}-$ $\mathrm{Zn}-2$ catalysts. 
was also observed. Absence of a band at $1800 \mathrm{~cm}^{-1}$ indicated absence of cyclic carbonate impurity in the polymer.

By achieving different catalyst properties through change in mode of addition of reagents, it was found that prime features governing activity of $\mathrm{Co}-\mathrm{Zn}$ catalysts for polycarbonate synthesis are complexing agent and Lewis acidity. Actual role of complexing agent is to activate the $\mathrm{Zn}^{2+}$ active centre rather than reducing crystallinity.

The XRD patterns of the fresh and spent Fe-Zn-1 and $\mathrm{Co}-\mathrm{Zn}-2$ catalysts were nearly the same (Supplementary information, S6). The CN stretching frequencies in FTIR of spent catalysts match those of the fresh catalysts appearing at 2096 (for Fe-Zn-1) and 2191 (for Co-Zn-2) $\mathrm{cm}^{-1}$, respectively (Supplementary information, S7). The spent Fe-Zn-1 showed an additional band at $1725 \mathrm{~cm}^{-1}$ corresponding to an adsorbed diacid molecule from the reaction mixture. These studies on spent catalysts, thus, confirm structural and chemical integrity even after their use in catalytic reactions.

\section{Conclusion}

A systematic investigation was carried out to identify the factors influencing catalytic activity of DMC in the synthesis of hyperbranched polyesters and aliphatic polycarbonates. Change in mode of addition of reagents in the synthesis resulted in $\mathrm{Fe}-\mathrm{Zn}$ and $\mathrm{Co}-\mathrm{Zn}$ catalysts with varying textural, structural and catalytic properties. Hydrophobicity (that facilitates adsorption of reactant molecules but not the by-product water), Lewis acidity (that initiates the esterification reaction) and micro-mesoporous architecture (that controls the gelation process) are the principle features of $\mathrm{Fe}-\mathrm{Zn}$ DMC catalysts control the production of hyperbranched polyesters of higher degree of branching without gelation. Higher amount of coordinated complexing agent and strong acidity are favourable factors for producing polycarbonate in high yield and with high $\mathrm{CO}_{2}$ content over the Co-Zn DMC catalysts. $\mathrm{CO}_{2}$ adsorption studies pointed out that high guest-host interaction led to reduction in induction period of polycarbonate synthesis. Polycarbonates with a molecular weight $\left(M_{\mathrm{w}}\right)$ of 14600 and PDI of 1.6 were synthesized over Co-Zn-2 DMC catalyst. This study lays the basis for future efforts in the rational design of highly active DMC catalysts for the synthesis of hyperbranched polymers and aliphatic polycarbonates through modification of crucial parameters such as hydrophobicity, acid strength, mico-mesoporosity and amount of coordinated complexing agent.

\section{Supplementary information}

Thermogravimetric analysis of $\mathrm{Fe}-\mathrm{Zn}$ and $\mathrm{Co}-\mathrm{Zn}$ catalysts, influence of reaction temperature and molar ratio of glycerol: diacid on the yield and DB of G-SA and G-AA polyesters, ${ }^{13} \mathrm{C}$ NMR and FTIR spectra of poly(cyclohexene carbonate) prepared using Co-Zn-2 and XRD and FTIR of spent catalysts are available as supporting information (figures S1 - S7) in the Journal of Chemical Sciences website (www.ias.ac.in/chemsci).

\section{Acknowledgement}

JS thanks the Council of Scientific and Industrial Research (CSIR), New Delhi, for the award of Senior Research Fellowship.

\section{References}

1. Yan D, Gao C and Frey H 2011 Hyperbranched polymers, synthesis properties and applications (New Jersey: Jhon Wiley \& Sons) 1

2. Segawa Y, Higashihara T and Ueda M 2013 Polym. Chem. 41746

3. Stumbé J F and Bruchman B 2004 Macromol. Rapid Commun. 25921

4. Wyatt V T, Strahan G D and Nunez A $2010 \mathrm{~J}$. Am. Oil Chem. Soc. 871359

5. Brandao R F, Auirino R L, Mello V M, Tavares A P, Peres A C, Guinhos F, Rubin J C and Suarcz P A Z 2009 J. Braz. Chem. Soc. 20954

6. Stille J K 1985 Pure Appl. Chem. 571771

7. Kulshresta A S, Gao W and Gross R A 2005 Macromolecules 383193

8. Sebastian J and Srinivas D 2011 Chem. Commun. 47 10449

9. Aresta M, Dibenedetto A and Angelini A $2013 \mathrm{~J} . \mathrm{CO}_{2}$ Utiliz. 3-4 65

10. Zevaco T A, Janssen A, Sypien J and Dinjus E 2007 Green Chem. 7659

11. Lu X B and Darensbourg D J 2012 Chem. Soc. Rev. 41 1462

12. Inoue $\mathrm{S}$, Koinuma $\mathrm{H}$ and Tsuruta $\mathrm{T} 1969$ Polym. Lett. 7 287

13. Kuran W, Pasynkiewicz S, Skupinska J and Rokicki A 1976 Makromol. Chem. 17711

14. Cheng M, Lobkovsky E B and Coates G W 1998 J. Am. Chem. Soc. 12011018

15. Cheng M, Moore D R, Reczek J J, Chamberlain B M, Lobkovsky E B and Coates G W $2001 \mathrm{~J}$. Am. Chem. Soc. 1238738 
16. Coates G W and Moore D R 2004 Angew. Chem. Int. Ed. 436618

17. Zevaco T A, Janssen A, Sypien J and Dinjus E 2007 Green Chem. 7659

18. Lu X B and Darensbourg D J 2012 Chem. Soc. Rev. 41 1462

19. Kember M R, Buchard A and Williams C K 2011 Chem. Commun. 47141

20. Pescarmona P P and Taherimehr M 2012 Catal. Sci. Technol. 22169

21. Darensbourg D and Wilson S J 2012 Green Chem. 14 2665

22. Jintang D, Jiajun W, Lianfang F, Long $\mathrm{W}$ and Xueping G 2010 J. Appl. Polym. Sci. 118366

23. Chen S, Qi G R, Hua Z J and Yan H Q 2004 J. Polym. Sci. Part A $\mathbf{4 2} 5284$

24. Yi M J, Byun S H, Ha C S, Park D W and Kim I 2004 Solid State Ionics $\mathbf{1 7 2} 139$

25. Dharman M M, Ahn J Y, Lee M K, Shim H L, Kim K H, Kim I and Park D W 2008 Green Chem. 10 678

26. Sebastian J and Srinivas D 2013 Appl. Catal. A: Gen. 464-465 51
27. Nakamoto K 1986 Infrared and Raman spectra of inorganic and coordination complexes (New York: Wiley)

28. Balmaseda J, Rguera E, Hernándes J R, Regurea L and Autie M 2006 Micropor. Mesopor. Mater. 96236

29. Roque J, Reguera E, Balmaseda J, Hernández J R, Reguera L and Castillo L F D 2007 Micropor. Mesopor. Mater. 10357

30. Hernández J R, Reguera E, Lima E, Balmaseda J, Martinez-Garcia R and Yee-Madeira H 2007 J. Phys. Chem. Solids $\mathbf{6 8} 1630$

31. Xu M, Yan X, Cheng R and Yu X 2001 Polym. Int. 50 1338

32. Pirez C, Caderon J M, Dacquin J P, Lee A F and Wilson K 2012 ACS Catal. 21607

33. Lee S, Baek S T, Anas K, Ha C S, Park D W, Lee J W and Kim I 2007 Polymer 484361

34. Krap C P, Zamora B, Reguera L and Reguera E 2009 Micropor. Mesopor. Mater. 120414

35. Chen M, Darling N A, Lobkovsky E B and Coates G W 2000 Chem Commun. 20002007

36. Nakano $K$, Nozaki $K$ and Hiyama T 2001 Macromolecules $\mathbf{3 4} 6325$ 